\title{
Situational language training for hotel receptionists
}

\author{
Frédérique Segond, Thibault Parmentier \\ Xerox Research Centre Europe \\ Meylan, 38240, France \\ segondexrce.xerox.com
}

\author{
Roberta Stock, Ran Rosner \\ The Marathon Group \\ Tel Aviv, Israel \\ rstock@marathon-group. net
}

\author{
Mariola Usteran Muela \\ Grupo gdt. \\ Sevilla, Spain \\ mustaran@grupogdt.com
}

\begin{abstract}
This paper presents the lessons learned in experimenting with Thetis ${ }^{1}$, an EC project focusing on the creation and localization of enhanced on-line pedagogical content for language learning in tourism industry. It is based on a general innovative approach to language learning that allows employees to acquire practical oral and written skills while navigating a relevant professional scenario. The approach is enabled by an underlying platform (EXILLS) that integrates virtual reality with a set of linguistic, technologies to create a new form of dynamic, extensible, goal-directed e-content.
\end{abstract}

\section{Credits}

The work described in this paper has been supported by the European Commission in the frame of the eContent program ${ }^{2}$.

\section{Introduction}

Thetis focuses on the creation and localization of enhanced on-line pedagogical content for language learning in tourism industry. It is based on a general approach to language learning that allows employees to acquire practical oral and written skills

\footnotetext{
${ }^{1}$ THETIS - Training for hotel employees to interact in situations (EDC- 42052). www.thetis-project.org.

${ }^{2} \mathrm{http}: / / \mathrm{www}$. cordis.lu/econtent/
}

while navigating a relevant professional scenario. The approach is enabled by an underlying platform $\left(\right.$ EXILLS $^{3}$ ) that integrates virtual reality with a set of linguistic technologies to create a new form of dynamic, extensible, goal-directed e-content

Thetis has two aims:

- Test the value of linguistic technologies for on-line language learning.

- Localize and repurpose existing e-content for English and vocational blended training material that was first designed for CDROM in order to offer it on-line. The material is meant to develop oral comprehension and reading skills in order to enable end-users to communicate with English speaking customers. It will be used for the continuous vocational training of professionals in this sector through the Internet as well as on-site.

In the following sections we present the following:

- The Thetis scenario and the technologies applied

- Aspects of content adaptation

- the results of the users' evaluation

- the lessons we have learned both regarding the value of the technologies (including the linguistics technologies), and the peda-

\footnotetext{
${ }^{3}$ See www.exills.com
} 
gogical value of such an innovative approach to language learning

\section{Thetis : scenario and linguistic tech- nologies}

As the general technical architecture behind Thetis has already been described in details in (Segond and Parmentier 2004) (Brun et Al. 2002) we just give an overview of the entire system and concentrate below on the description of the Thetis scenario and on the linguistic technologies that have been integrated into the system.

Thetis integrates virtual reality and linguistic technologies in a web application in order to propose a truly e-learning solution that can be used both synchronously and asynchronously. Our motivations for applying these two components are the following:

- Virtual reality offers a cognitive context and promotes interaction.

- Linguistic technologies offer autonomy to the students by showing them concepts, giving them assistance to understand word meanings within particular contexts by presenting various examples, providing feedback on their skills (during chat sessions as well as through exercises or even free activities).

The notion of scenario is central to Thetis. The scenario allows the users to act in typical work situations such as introducing themselves, reading emails, searching for and understanding information, ordering a meal, and interacting with colleagues and customers. The lessons include traditional contents such as grammar rules, exercises, and speech acts. The users interact either via chatting or during the different activities proposed. The Thetis scenario has been explicitly designed for people working at hotels' reception desks.

\subsection{Scenario}

Students and tutors enter a virtual reality scene either all together at the same time (synchronously) or whenever they want (asynchronously). They are then in a virtual hotel where they are given roles that correspond to the different prototypical hotel situations listed above. All students have to play their everyday job, hotel desk receptionist. They interact with customers. The tutors can choose the role they play: customers, fellow students or tutors. The resulting system can be used either individually from any place with access to the Internet or collectively, all or some students being in the same location (open class, hotel etc.)

The customers are robots and the students are avatars that work at the reception desk.

The robots are 3D-human representations that have been programmed in advance. They can invite users to chat, react to certain stimuli such as predefined lists of words or movements of others in the 3D-scene.

The avatars are non-programmed 3D-human representations of users. The users can decide where to go in the virtual scene, with whom they want to interact, what to say.

The application is composed of several virtual rooms. Each of these rooms corresponds to a different scenario related to the receptionists work tasks.

The students' avatars interact either with the robotcustomers, or among themselves. The language of the interactions is exclusively the language being learned i.e. English, (which is automatically checked by the system). In order to encourage interactions among the students and to strengthen the playful aspect of the course, the students are asked to work in groups of two or three. Each group of two or three students enter rooms at the same time, and interact individually with different robot customers. Since they are in the same room they are also able to communicate among themselves, in the language they learn, when they have difficulties. The tutor can also be present. There is a common back room where all the students can go any time to interact with the rest of the student group, be it because they need help or because the tutor asks for a meeting.

In order to call for interaction students and tutors can either type text in the chat window or, in some 
specific cases (previously defined in the scenario) record their answer and send the speech file to the tutor.

The figure below is a snapshot of the different activities in the different virtual rooms. Traditional linguistic exercises, cards with grammar or speech act hints are associated to the activities of each room.

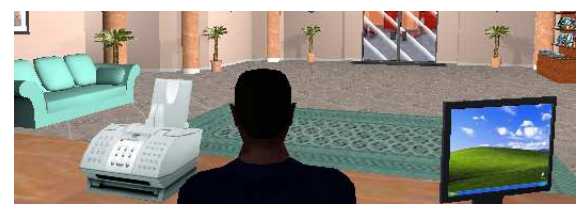

In the Virtual World students always have access to a phone, a fax, a reservation book, computers, documents internal to the hotel (regulations, menu, price lists, tourist information etc.).

During the different activities, the students interact with robots that play different roles (customers, travel agents, taxi driver etc.). Dialogues between students and robots work as follows: the students type some text in the chat box, and the robots reply orally. Robot participations to dialogues are prerecorded sound files. The robots are configured to reply to stimuli like a new learner arriving in a scene asking for a private chat, etc. For instance, when a student asks a question, the robot can automatically select the most appropriate answer or action based on the dialog's steps or based on keywords found in students' written production.

\section{Examples:}

"Could you show/give me your identity card?" would produce the action of displaying a window with the image of an identity card.

"How long will you stay?" would produce an answer like "three nights".

When robots ask questions, the students' answers can be used (or not) to select the next move in the dialogue.

\section{Examples:}

Robot: "Do all the rooms have an Internet connection?" Student: "No" would imply a specific notice on the reservation fax to require an Internet connection.

\subsection{Linguistic Technologies}

In terms of tools and resources available in the virtual world, the students have access to real hotel documents (including a list of hotel services, prices and regulations, real identity documents from different countries, etc.)as well as to linguistic technologies.

The linguistic tools include the following:

- A comprehension help that provides students with the most appropriate contextual translation of any word or expression. Comprehension help is crucial in speeding up both the students' comprehension and written production.

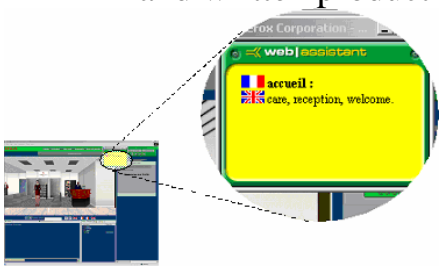

- A linguistic tool box that provides the students with customizable services which allow them to parse and to tag their own production in order to check its correctness.

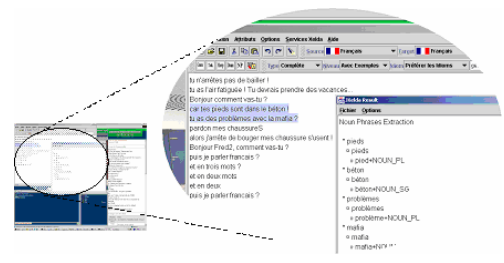

- A morphological analyzer that gives the students access to conjugations or declinations.

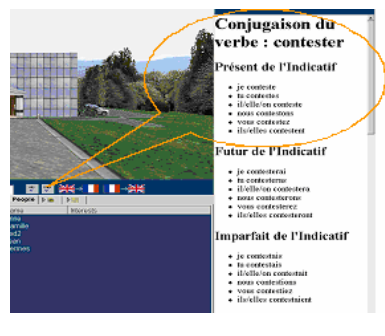

- A language guesser that automatically prevents students 


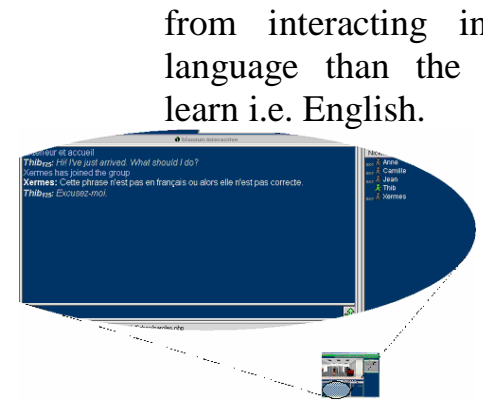

\section{Good quality content}

The other interest of Thetis is to create and adapt econtent to offer it on-line rather than on CD-ROM. One of the most difficult issues that e-learning faces is global delivery, especially with the challenges of localization and repackaging content for different audiences. Europe has been active in creating high quality pedagogical content for years and is genuinely concerned about languages.

Over the past few years, multimedia publishers have developed electronic content for language learning of very high pedagogical value and very good quality. With the arrival of e-learning, they see their work changing and do not always have the necessary expertise and resources to take the e-learning route.

Indeed e-learning revolutionizes the training domain as it provides personalized, real-time training and communications programs, rather than a "one size fits all" approach. To take advantage of the potential of e-learning, multimedia publishers need to develop expertise in Internet technologies in general. To be able to put their content on-line they need to work in partnership with companies that have Internet expertise and document processing technologies. On the other hand, technology providers in the area of e-learning have given very little attention to the quality of the content that will be offered, to the pedagogical aspect of e-learning as well as to the question of what needs to be changed in order to use the Internet to train people. Most of the e-learning companies have tried to sell platforms to content providers rather than trying to work in partnership with them in order to create good-quality e-learning solutions. It is certainly not enough to integrate content that has been built for another purpose (to teach in face to face meetings for example, or even for CD-ROM distribution) with technologies to make a good training module. Pedagogical aspects must be considered and technologies should support pedagogy rather than being the main objective.

\section{1 eContent adaptation}

Thetis particularly concentrated on defining the virtual environment and the content of the training, adapted to the needs of the employees in a hotel reception.

The main functions of receptionists are presenting a positive image of the hotel and assisting with all aspects of guest service; they act as buffers between the customers and management of the hotel.

The training needed to take into account their main duties, including the following:

Answering enquiries regarding hotel services and registration by letter, telephone and in person

Making room reservations

Registering arriving guest and assigning rooms

Responding to guests' enquiries, requests and complaints

Using computerized or manual systems to compile and check daily record sheets, guest accounts, receipts and vouchers

Presenting statements of charges to departing guests and receiving payment

Additional duties, which may be required by small hotels.

It was also important to consider the skills needed by these kinds of workers, even when they need to communicate with customers in languages different from theirs.

Good communication skills and a neat appearance are essential for hotel receptionists. They need basic analytical skills and experience with word processing equipment and computers. Good judgment is necessary, as well as ability to solve problems in a bold way and with determination, since they may have to deal with difficult people, as well as with emergency and security problems. 
But one of the best assets is the knowledge of, at least one, second language. To communicate fluently with customers in a foreign language, solve problems and deal with complaints, turn them into opportunities is the aim of this project, together with the development of key competences for employees working at hotel reception desks, such as efficiency, courtesy, initiative, capability of working in team and communication skills, among others.

What is different in Thetis, compared to "traditional CD-ROM content" building are the scenarios through which the courses will be delivered to hotel receptionists. So the content had to be appropriate to the scenarios so that it is adapted to the learning context, and it had to be localized following the target region of the training.

The pedagogical content is realized on different media like texts, audio support, and videotapes. For each medium different activities are available in order that the students can practice a specific grammar point, an idiomatic structure or phrase. There are several kinds of exercises each corresponding to a lexical area and/or speech act. This means that a student is immersed in a work situation associated with specific difficulties in grammar and vocabulary and (s)he is provided with exercises helping to develop her/his competencies.

The objective is not to find a typical situation in order to learn a specific grammar point or an idiomatic structure. The process is rather first to list the typical work situations the hotel receptionists are confronted with and afterwards to identify the language difficulties associated with each situation and, in a third time, to select the media, the content, the type of activity that is the best suited to help the students to deal with the work situation. One other difficulty is to propose a sequence of working activities that also match with the language and vocabulary level of the student.

Besides the scenario, the students are also provided with some classical content in order to help them to meet the needs they could be confronted with outside typical training situations. Such classical content is listed in the points below:

- a grammar book containing a list of all the sentence patterns and forms that are used in the program with explanations of their use and form;

- a lexicon with English headwords, examples of usage and explanation or translation into native language. Students also have the option of hearing the pronunciation of new items;

- student records which allow students to monitor their own progress,

- technical help in order to present the characteristics of the delivery web application.

This existing content has been adapted to the tourism industry

Although the basic content will be the same for all target audiences, the addition of elements that appeal directly to each target user group makes the product attractive and motivating.

In terms of language practice, it is also possible to place an emphasis on those items that cause particular problems to specific language groups.

As far as already existing content related to tourism scenarios is concerned, they had to be adapted to our purposes: some pedagogical activities had to be reversed because they had been developed in order to help a customer, a tourist in our case, to interact with other people i.e. receptionists, waiters/waitresses, passers-by. The main task was to propose mainly the same activities but for training receptionists.

\section{$5 \quad$ Users' tests}

The content of the course focuses on teaching English to hotel receptionists. Therefore, the users were faced with real situations that occur in hotels within the context of their everyday work environment. The objective then was to test the course within this target group in order to analyse its potential use, and possible adaptation to any socioprofessional domain, as well as extension to any language.

The main elements of THETIS that needed to be tested are the following:

- Technical issues: linguistic tools, virtual reality 
- Pedagogical effectiveness: quality of content, game aspects, etc.

- Work related competencies: hotel environment and situations, level of interest, relevance, etc.

There were two major groups of users involved in these tests:

- Students

- Teachers or tutors.

All students involved (18) are currently students of a Hotel Management vocational training program organised by the Andalusian Entrepreneurial Confederation (CEA).

The profile of the group was the following: $80 \%$ were between 20 and 24 years old, $20 \%$ were between 25 and 30 years old. All of them have a university degree in Tourism. $80 \%$ had previous work experience in hotels or tourism related jobs. $50 \%$ had an intermediate competency level in English, $17 \%$ low intermediate and $33 \%$ high intermediate.

A team of 3 teachers was also involved in this test; one of them was present at the location of the test activities and the other two were doing participated from another country, which shows the flexibility that distance learning offers.

Each session followed the same structure:

- Presentation of the three partners.

- Presentation of the THETIS project.

- Goals and objectives of the session.

- Explanation of the different elements of THETIS:
○ Chat
○ Virtual Reality
○ Dictionary
○ Verb conjugation
○ History
○ Notes

\section{○ Grammar \\ $\circ$ Exercises}

After the initial explanations, the session continued by proposing different activities in which the students had to do the following:

- Chatting among students - learning games. A reservation form had to be filled out. Each form contained some information of different customers. We assigned one specific guest to each student, so they had to discuss and ask each other about the missing data.

- Chatting with the teacher - role playing exercises. The teacher acted as a customer and started different dialogs with the students based on typical hotel situations such as making reservations or asking for directions.

- Exercises. The students were given time to practise four categories of exercises: reading comprehension, grammar, listening and vocabulary.

- Interacting with the robots. The students had to take part of the pre-set dialogs with the customer-robots at the virtual reality scenario and choose the right answer in every situation.

Once the testing activities described were finished, the students were asked to write their comments by answering a complete questionnaire

Most of the students agreed that using this program continuously as part of complete language training would be very beneficial. Some students appreciated most that it helped remember expressions and vocabulary they had learnt before, so it was good practice. Most of them acknowledged the acquisition of the specific language used in hotels and the expressions needed in situations that occur at the front desk.

Regarding the scenario itself all students considered that what happens in a hotel and the daily functions that a receptionist must carry out are very 
well represented. Some typical appreciations are the following:

\section{"It is a very creative way to reflect the different situations happening in a hotel"}

"Doing different things at the same time is very common at hotels and getting to learn English by having the same experience is crucial"

"It is good that we get to see the nice things that normally happen but also the not so nice ones, like dealing with upset customers"

Basically, the main advantages of THETIS appear to be how realistic the situations are, the entertaining and fun part of learning and the interaction with the teacher and the other students.

As for the weaknesses, these appear to be related to the fact that Thetis is still a pilot product and some technical and content details have yet to be finalized.

Regarding the elements the testers found most useful during the learning process, we found a broad range of answers and every tool was named. Regarding the linguistic technologies students mentioned the contextual dictionary look-up as the one they made the most use of. However, the elements that received a higher appreciation were the interaction with robots (virtual reality) and with the teacher (chat), because of the entertaining aspect they both bring, the realistic feature they portray as well as their practical application.

In order to have a complete and enriched information report, we asked for the teachers' opinion as well.

It was perceived that through this program students are given different ways to consolidate what they learn which makes it quite efficient. It is also important to say that there is a clear need to have teacher-student interactions to make it more successful pedagogically, since this element gives the students the opportunity to use free and authentic language and to be corrected in real time.

Since interactions between the teacher and the students are allowed through chat - which is something the students enjoyed a lot - it was remarked that the teacher needs to have the possibility to cor- rect mistakes. So for this tool to be more useful and not damaging the role-playing situation, there is a need to find a way to send the students that feedback, for example, by making it appear in another color.

It is also important to prepare different possible scenarios/exercises for the teachers to develop through the chat. Therefore, it appears important to prepare a teacher's guide.

\section{Conclusion: lessons learned}

In general, we found that the creation of content for a Thetis like type of concept was not a trivial and easy task. Indeed Thetis provides a solution that is strongly web oriented in the sense that it insists on interaction on the web, personalization and information access. As a consequence the type of content that fits these requirements is radically different from ones that already exist for other supports such as, for instance, CD-ROMs. We did not expect this adaptation to be so time consuming. It turns out that while a "traditional" type of CDROM content can be integrated in the form of exercises within the Thetis solution, it is necessary to build new types of content in the form of scenarios. Indeed the notion of a scenario, which is central to Thetis as well as its strong point, means one that covers both learning a language and learning a work practice. This scenario should also be attractive and evolving enough so that it retains students' interest and motivation. The borderline is sometimes difficult: we need to be careful not only to propose games where students learn how to do their work but not so much how to speak a language. Moreover, the scenarios, since they take place on the web and in a virtual world, cannot be like the ones that are proposed in a face to face course. Interaction is different. Robots plays a central role in pushing people to interact with each other, and so does the tutor. How to make the best pedagogical use of these two aspects? What is the type of dialogues that work better in terms of pedagogical purposes?

During the testing we had had various comments on the specific features offered by the system as well as suggestions for improving it; all of them would need to be further tested. These suggestions 
come from different perspectives: from the tutors and from the students.

As far as the tutors are concerned, while they find the idea really interesting pedagogically, they also generally consider it difficult to interact with several students at the same time. For instance correcting several students in the chat is almost impossible. Therefore they ask for tools to help them in this process. These tools would be like the ones that already exist in current management systems courses, and they would have to be enriched with some specific functions to deal with on-line interaction. Teachers usually liked a lot the language guesser module as it forces students to interact in the language they learn and relieve them from checking that students do not interact in their own language.

On the opposite side, the students liked and used a lot the contextual on-line dictionary because they really want to play and interact and are forced to do so in the foreign language. The students definitively liked the virtual reality and the game aspect. The strongest point of Thetis is undoubtedly the interactions based on a virtual reality scenario as compared to e-mail interactions, chats or forums. Probably owing to the virtual world shy people tend to participate much more than usual. This is also the feedback that we got from tutors concerning their students.

While students enjoyed the game very much, this would need to be tested on the long run as Thetis certainly benefits from the "novelty effect".

Both teachers and students would like to be able to speak rather than just to write. However, it is not clear how this type of interaction would be possible in virtual reality with 15 people not being able to see each other. During the project, we identified strong points as well as difficulties and gaps. The main difficulty is in the type of content that fits Thetis' philosophy. Indeed, building such content requires more time than we first expected. While part of the content can be just repurposed and localized from already existing materials, a completely new type of content needs also to be created from scratch. Users made interesting suggestions regarding the integration of new technologies such as speech processing or tools for the tutors. These would require further testing.

\section{References}

Brun C., Parmentier T., Sandor A., Segond F., 2002, Les outils de TAL au service de la e-formation in Multilinguisme et le traitement de l'information, Frédérique Segond Ed., Hermès, pp. 223-251

Frase, L., R. Almond, J. Burstein, K. Kukich, R. Mislevy, K. Sheehan, L. Steinberg, and K. Singley and M. Chodorow. (2002). In H. O'Neill and R. Perez (Eds.) Technology Applications In Education: A Learning View. Lawrence Erlbaum

Kashny M., Les usages des Technologies d'Information et de Communication par des enseignants dans un dispositif de formation tutorée en langues vivantes étrangères. Une approche ergonomique. Thèse Université Pierre Mendès France, 2001, Grenoble.

Kearns M., Satinder Singh C., Litman D., and Howe.J. CobotDS, 2002: A Spoken Dialogue System for Chat. In Proceedings of the Eighteenth National Conference on Artificial Intelligence (AAAI-2002), Edmonton, Canada.

Kindley, R., Scenario-Based E-Learning: A Step Beyond Traditional E-Learning, http://www.learningcircuits.com/2002/may2002/kind ley.html

Kukich, K , 1992, Technique for automatically correcting words in text, ACM Computing Surveys (CSUR)

Volume 24 , Issue 4, ( $377-439)$

Paulsen, J. (2001-section 4). "Authentic Online Target Language Reference Resources." New Era Trends and Technologies in Foreign Language Learning: An Annotated Bibliography - Interactive Multimedia Electronic Journal of Computer-Enhanced Learning, April 2001, Wake Forest University.

Puren, C. Histoire des méthodologies de l'enseignement des langues, Clé International, Nathan, 1988, Paris.

Segond F, Parmentier T, 2004 NLP serving the cause of language learning Proceeding of International Workshop on eLearning for Computational Linguistics and Computational Linguistics for eLearning COLING, Geneva 